\title{
Polyurethane adhesives in flat roofs
}

\author{
Markéta Bogárová ${ }^{1, *}$, Jindřich Stodůlka ${ }^{1}$, and Karel Šuhajda ${ }^{1}$ \\ 'VUT FAST, Ústav pozemního stavitelství, Veveř́ 331/95, 60200 Brno, Czech Republic
}

\begin{abstract}
It is necessary to stabilize individual layers of flat roofs, mainly because of wind suction. Apart from anchoring and surcharge, these layers can be secured by bonding. At present gluing is an indispensable and widely used stabilization method. On our market we can found many types of adhesives, most widely used are based on polyurethane. This paper focuses on problematic about stabilization thermal insulation from expanded polystyrene to vapor barrier from bitumen. One of the main issues is to calculate the exact amount of adhesive, which is required to guarantee the resistance against wind suction. In this problematic we can not find help neither in technical data sheets provided by the manufactures. Some of these data sheets contain at least information about amount of adhesive depending on location in roof plane and building height, but they do not specify the strength of such connection. It was therefore resorted to select several representatives polyurethane adhesives and their subsequent testing on specimens simulating the flat roof segment. The paper described the test methodology and results for two types of polyurethane adhesives.
\end{abstract}

\section{Introduction}

Flat roofs are mostly designed as single-shell or double-shell. Single-shell roofs provide all function with just one shell that is formed from a few layers. Every layer in the roof shell has to be secured from wind suction.

Among of all sorts of stabilization, gluing is technology that is the most inclinable to extreme conditions. In this case it means especially planeness, cleanliness of base and weather conditions. On the contrary, big advantage of stabilization by gluing is unoverloading of construction, it doesn't come to perforation of lower layers, neither to bringing point thermal bridges into construction. In terminological formulation, gluing is the layer connecting two near-by layers of the roof shell. This connecting layer is designed of proper adhesives intended for these purposes. It is preferred to use adhesives which are not able of permanent plastic deformation by expected temperatures after application.

\section{Polyurethane adhesives}

Polyurethane adhesives rank among adhesives based on synthetic base indurative with access to air humidity.

\footnotetext{
*Corresponding author: bogarova.m@,fce.vutbr.cz
} 
Double-component polyurethane adhesives are based on reaction of multi-substantial alcohols (polyols) with multifunctional isocyanates. This reaction proceeds very fast attended by creation of dense polymer web.

Mono-component polyurethane adhesives were made of double-component so that polyol was kept to react with abundance of isocyanate. Therefore there were groups of isocyanate that didn't react with each other. These are sensitive to water, alcohols, amines, acids etc. Adhesives setting happens by activity of air humidity in three steps. In the first step it comes to reaction of isocyanate with water and therefore to creation of unstable carbamic acid. The second step is disintegration of karbam acid to carbonic oxide and amine. And the third step is reaction of amine and isocyanate and creation of polyurethane linkage [1].

In the most cases of gluing in flat roofs in the Czech republic, there are used monocomponent polyurethane adhesives.

\subsection{Gluing issue}

When we use polyurethane adhesives as connecting layer and core method of stabilization of flat roof shell as well, many questions about function of glued system arise. Mainly it is about amount of used adhesive and accompanying stability of glued joint. Of course, there are other influences in this whole process such as material of connecting layers, extreme conditions or type of adhesive.

Composing of glued joints in the flat roof hasn't standards or legislatively formed any parameters, if it is about amount of glue or stability of formed joint. Technical data sheet from manufacturers often contain advised amount of adhesive, but no reached stability of glued joint.

By this reason, it came up to testing of glued joints. Testing methodology was created that was based upon ČSN EN 1607 Thermo-insulating products for building applications Determination of tensile strength perpendicular do faces [2-5].

\subsection{Testing methodology}

In this methodology, it was necessary to design test model and test apparatus that would be easy and repeatedly attached to test model and also vised into press. In this article, one type of test model will be described with using two types of polyurethane adhesives.

\subsubsection{Test model}

Test model consists of modified asphalt strip and expanded polystyrene EPS $150 \mathrm{~S}$. These two layers were connected by polyurethane adhesive or the testing joint. To create this test model, it was necessary to provide these two layers with desk tough enough to transfer tension power of whole surface from test apparatus to test joint. Therefore, beech plywood was chosen for its mechanical features. Connection with tough desks was solved with melting of the asphalt strip on its whole surface and also with gluing to polystyrene with polyurethane adhesive on its whole surface. 


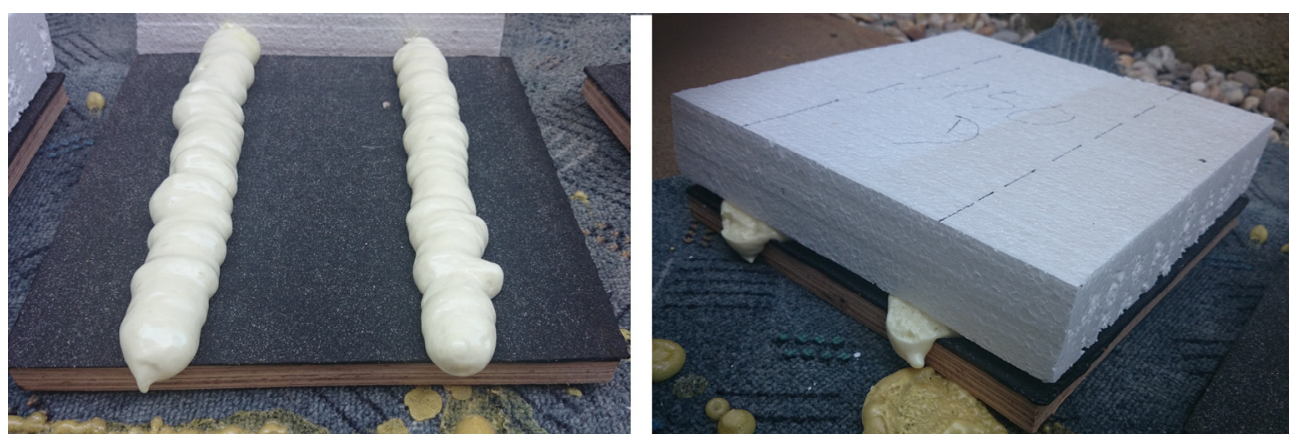

Fig. 1. Creation of test model with testing joint between asphalt strip and thermo-isolation.

\subsubsection{Test apparatus}

As you can see on Fig. 2, test apparatus was made of iron plate with 8 holes for mechanical attaching to test model with screws and with hard-faced unwrought extension hexagonal female screw with thread. Others parts of test apparatus were threaded rods used for attaching to jaws of the press.

Test apparatus was always put to the center of test model and thus axial stress was secured. Used press has fixed upper jaws and the speed of stalling of lower jaws was set to $10 \mathrm{~mm}$ per minute. Record of grow of tension stress, time and moving of crossbar till to failure of test model was taken in this measurement. Test result was the maximum tension stress above all.
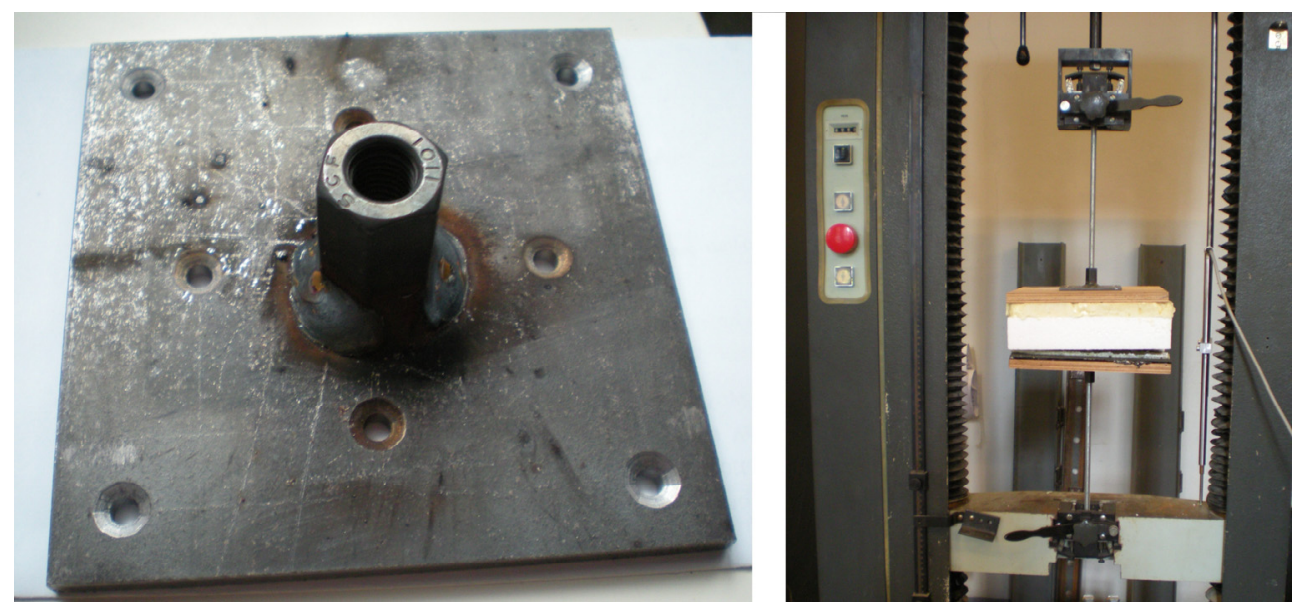

Fig. 2. Iron plate of the test apparatus on the left and gripping of the test model in press on the right.

\subsection{Experimental measurement}

The experimental part of this article is about comparison of two types of polyurethane adhesives by using sample size $250 \times 250 \mathrm{~mm}$ with polyurethane adhesive in two stripes. Gluing itself happened in outdoor condition with $21^{\circ} \mathrm{C}$ temperature and $88 \%$ relative air humidity. Following testing was taken after two weeks in lab conditions with $23 \pm 2{ }^{\circ} \mathrm{C}$ air temperature. There was used 10 pcs of test samples per each testing adhesive's type, still in some cases distortion outside of tested joint happened. 


\subsubsection{Test model with tested adhesive number 1}

Table 1. Results of experimental measurements.

\begin{tabular}{|c|c|c|c|c|c|c|c|}
\hline Test sample nr. & $\mathbf{1}$ & $\mathbf{2}$ & $\mathbf{3}$ & $\mathbf{4}$ & $\mathbf{5}$ & $\mathbf{6}$ & $\mathbf{9}$ \\
\hline $\mathrm{F}_{\max }[\mathrm{N}]$ & 2846,9 & 3865,7 & 4015,8 & 3633,1 & 3267,0 & 3318,4 & 2813,1 \\
\hline$\sigma_{\mathrm{mt}}[\mathrm{kPa}]$ & 45,6 & 61,9 & 64,3 & 58,1 & 52,3 & 53,1 & 45,0 \\
\hline $\bar{x} \sigma_{\mathrm{mt}}[\mathrm{kPa}]$ & \multicolumn{7}{|c|}{54,31} \\
\hline$\sigma[\mathrm{kPa}]$ & \multicolumn{7}{|c|}{12,96} \\
\hline $\mathrm{V}_{\mathrm{x}}[\%]$ & \multicolumn{7}{|c|}{12,81} \\
\hline
\end{tabular}

Test samples with adhesive number 1

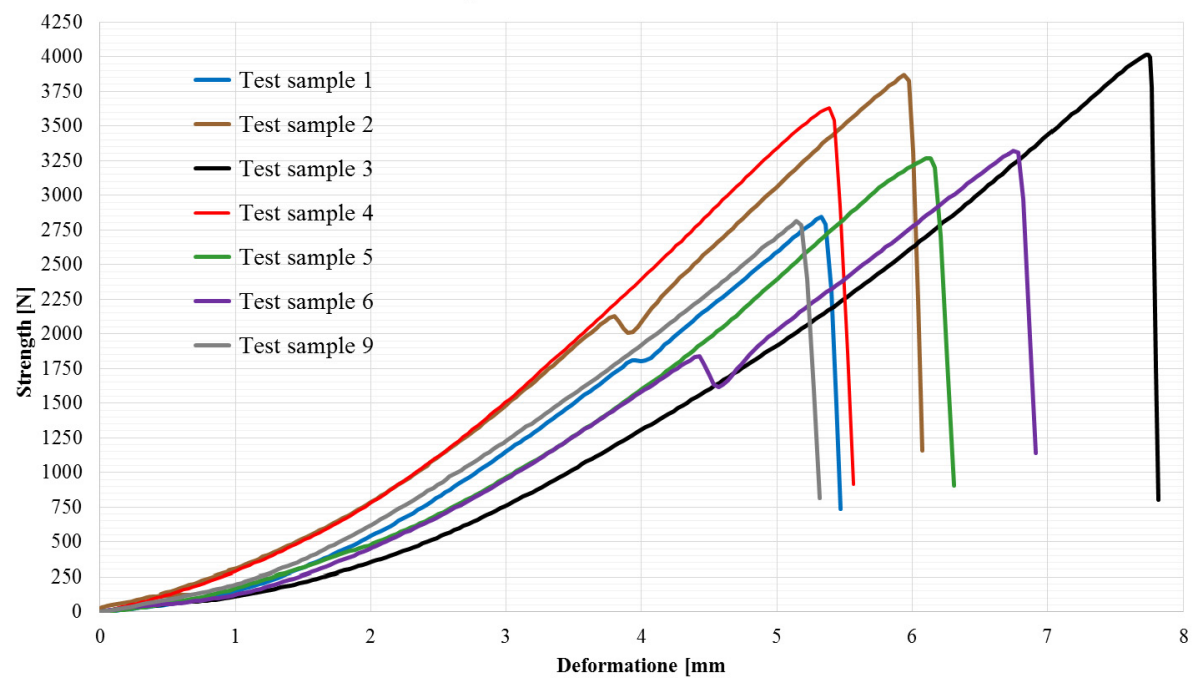

Fig. 3. Graph of results of individual test samples.

\subsubsection{Test model with tested adhesive number 2}

Table 2. Results of experimental measurements.

\begin{tabular}{|c|c|c|c|c|c|c|c|}
\hline Test sample nr. & $\mathbf{2}$ & $\mathbf{3}$ & $\mathbf{4}$ & $\mathbf{5}$ & $\mathbf{7}$ & $\mathbf{9}$ & $\mathbf{1 0}$ \\
\hline $\mathrm{F}_{\max }[\mathrm{N}]$ & 2183,7 & 2762,0 & 5128,0 & 2313,8 & 1575,2 & 3821,8 & 5162,1 \\
\hline$\sigma_{\mathrm{mt}}[\mathrm{kPa}]$ & 34,9 & 44,2 & 82,1 & 37,0 & 25,2 & 61,2 & 82,6 \\
\hline $\bar{x} \sigma_{\mathrm{m} t}[\mathrm{kPa}]$ & \multicolumn{7}{|c|}{52,45} \\
\hline$\sigma[\mathrm{kPa}]$ & \multicolumn{7}{|c|}{21,43} \\
\hline $\mathrm{V}_{\mathrm{x}}[\%]$ & \multicolumn{7}{|c|}{40,86} \\
\hline
\end{tabular}




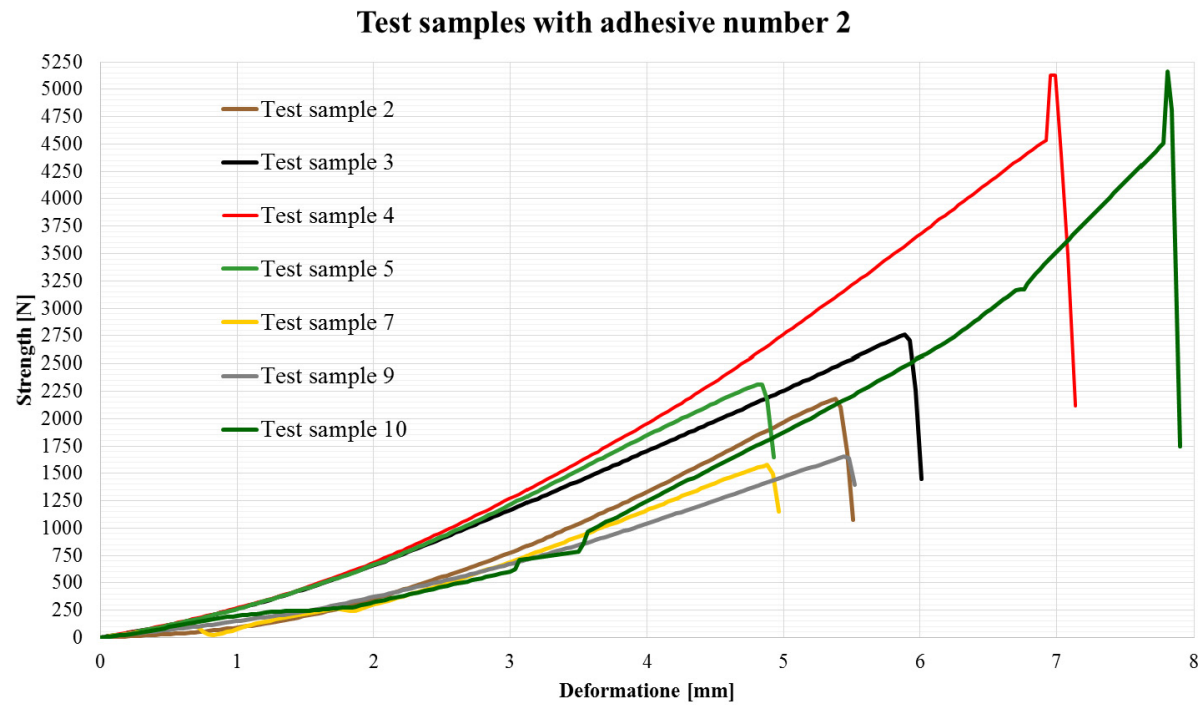

Fig. 4. Graph of results of individual test samples.

\subsubsection{Evaluation}

In this article above, there are presented results for two polyurethane adhesives using the same composition of test model. As you can see on Fig. 3, the adhesive numbered 1 embodied average value of tension $54,31 \mathrm{kPa}$ by directive deviation $6,96 \mathrm{kPa}$. Adhesive numbered 2 embodied similar average value of tension as adhesive numbered 1 and it was $52,45 \mathrm{kPa}$, but with directive deviation 21,43 kPa. From the graph of adhesive nr. 2 we can see that test samples 4 and 10 embodied markedly higher values and with distortion it has come to detachment of considerable part of polystyrene. In view of the fact that all samples were executed by the same extreme conditions and by using of the same materials, we can ascribe this effect to just varied properties of concrete polyurethane adhesive in one pack or to heterogeneity of the structure of expanded polystyrene. Of course, in this whole process we must apply the human factor, but parameters of particular layers are always checked (e.g. weight of adhesive, position of gluing stripes etc.) Considering this we can assume deviations created by executing test apparatuses cannot have large effect upon results. Also in others tests samples, it came to adhesive breakage between adhesive and polystyrene. In some test samples, adhesive embodies better connectivity with polystyrene than with asphalt's surface. This fact has been demonstrated by dividing adhesive between surfaces.

\section{Conclusion}

There were stated only results of measurements within the scope of two types of test models in this report. But also from these result we can see that gluing embodies strength values in such a dispersion. This fact is affected mainly by changing surface of concrete adhesive, but as it came from other measurements it's affected by many extreme conditions/side effects.

This article was supported by specific reserch project: FAST-S-16-3345 "Verifikace chování a rozvoj konstrukcí a konstrukčních prvků na bázi dřeva a kombinovaných konstrukcí ze dřeva a železobetonu" on Faculty of Civil Engineering VUT in Brno. 


\section{References}

1. Basic theory of gluing. ABClepidla.cz, (2013), online: http://www.abclepidla.cz/Files/file/files/Teorie_lepeni.pdf

2. CSN EN 1607. Thermal insulation products for building applications - Determination of tensile strength perpendicular to faces (ÚNMZ, Prague, 2013)

3. CSN 73 1901. Designing of roofs - Basic provisions (ÚNMZ, Prague, 2011)

4. J. Plachy, J. Musílek, Material for building, 19 (3), 33-37 (Business Media CZ s.r.o., Prague, 2013)

5. A. Fajkos, M. Novotny, Roofs - basic constructions (Grada Publishing, a.s., Prague, 2003) 